\title{
National survey of notifications of tuberculosis in England and Wales in 1988
}

\author{
Medical Research Council Cardiothoracic Epidemiology Group ${ }^{\star}$
}

\begin{abstract}
Background A survey was undertaken to determine the distribution of tuberculosis in England and Wales and, by comparison with the findings of similar surveys in 1978-9 and 1983, to study trends in the incidence of the disease by ethnic group over the decade.

Methods The survey included all cases of tuberculosis in England and Wales newly notified to the medical officers for environmental health during the six months from 2 January to 1 July 1988. Notification rates were calculated from population estimates from the 1988 Labour Force Survey.
\end{abstract}

Results Clinical details were obtained from the clinician for $2149(99.4 \%)$ of the 2163 newly notified and previously untreated patients. Over $90 \%$ were either white $(53 \%)$ or of Indian, Pakistani, or Bangladeshi ethnic origin (39\%). The notification rate in the white population was $4 \cdot 7 / 100000 / y e a r$, a decline of $7 \cdot 2 \%$ per year since 1978. The rate was 134.6 / $100000 /$ year in the population of Indian ethnic origin, and $100 \cdot 5 / 100000 /$ year in that of Pakistani or Bangladeshi ethnic origin, a decline of $6 \%$ a year since 1978 for the two groups combined (standardised for age, country of birth, and length of time in the UK). In all ethnic groups rates of disease were much higher in the elderly than in the young. Bacteriological results were available in $1161(80 \%)$ of the 1443 pulmonary cases. In $939(81 \%)$ Mycobacterium tuberculosis was cultured; 614 cases (53\%) also had positive smears, of which $424(69 \%)$ were from white patients.

Conclusions Notification rates for tuberculosis in England and Wales declined over the decade, but major differences remained between ethnic groups.

(Thorax 1992;47:770-775)

The incidence of tuberculosis in England and Wales, as judged by notification rates, has fallen substantially this century. In the 1960 s, however, there was a slight reduction in the rate of decline which coincided with the observation of an increasing proportion of cases from immigrant groups. ${ }^{1}$ Because the statutory notification system does not record ethnic origin or country of birth, the effect of immigration on the epidemiology of tuberculosis in Britain can be assessed only by special surveys. Such information is needed for policy decisions about BCG vaccination programmes and other aspects of the prevention and control of tuberculosis.

The Medical Research Council (MRC) Tuberculosis and Chest Diseases Unit undertook national surveys of cases notified in $1978-9^{2}$ and $1983 .^{3} \mathrm{~A}$ third survey, undertaken in 1988 and reported here, permits changes over the decade to be studied as well as the current incidence and distribution of tuberculosis in England and Wales.

\section{Methods}

The data were collected in the same way as in the surveys of $1978-9$ and $1983 .^{23}$ The medical officers for environmental health throughout England and Wales provided copies of all tuberculosis notification forms they received during the survey period, and the copies were checked against the weekly infectious diseases returns sent to the Office of Population Censuses and Surveys. All cases of tuberculosis reported to the Office of Population Censuses and Surveys from 2 January to 1 July 1988 were included.

Physicians were asked to complete a survey form whenever they notified a patient with tuberculosis during the period of the survey. The notifying doctor was approached directly for further information about any notification for which a survey form was not received.

The information requested on the survey form included the ethnic origin of the patient, country of birth and year of first arrival in the United Kingdom, site of disease, and results of any bacteriological investigations. In addition, the six regional centres for tuberculosis bacteriology and the Mycobacterium Reference Unit of the Public Health Laboratory Service provided results of sensitivity tests on all first isolates of Mycobacterium tuberculosis.

In the two previous surveys copies of chest radiographs for independent assessment were obtained for patients with a respiratory lesion; but, as there was very little difference in the distribution of radiographic characteristics of disease between the 1978-9 and the 1983 surveys, films were not requested in 1988 .

For the calculation of rates of disease num
Received 21 April 1992 Returned to authors 17 June 1992

July 1992

Accepted 22 July 1992

Hod


Table 1 Notifications of tuberculosis in six months

\begin{tabular}{lrrr}
\hline & $1978-9$ & 1983 & 1988 \\
\hline Notifications to medical officers for environmental health & 4838 & 3839 & 2748 \\
Duplicate notifications & 77 & 107 & 71 \\
Exclusions & 363 & 207 & 105 \\
Patients receiving chemoprophylaxis & 34 & 11 & 4 \\
Patients already notified & 105 & 104 & 51 \\
Diagnosis changed by physician & 69 & 101 & 106 \\
Disease due to mycobacteria other than $M$ tuberculosis & 0 & 3 & 0 \\
BCG abscess & 18 & 4 & 0 \\
Inactive disease notified after death & 0 & 0 & 3 \\
Patient not resident in the UK & 440 & 300 & 245 \\
Patient previously treated for tuberculosis & 3732 & 3002 & 2163 \\
Total newly notified previously untreated patients & 4496 & 3609 & 2669 \\
No of notifications reported to the Office of Population Censuses and Surveys ${ }^{\star}$ & &
\end{tabular}

^Includes previously treated patients as well as many of the exclusions.

bers of cases in the whole year were estimated by multiplying notifications in the six month period by a scaling factor $(1.9348)$ based on the proportion of notifications in 1988 reported to the Office of Population Censuses and Surveys in the six months of the survey. Population estimates were obtained from the 1988 Labour Force Survey (Office of Population Censuses and Surveys, commissioned tables); as in previous surveys, the small proportion of subjects whose ethnic origin was not stated were distributed in proportion to the population for whom ethnic origin was known.

In the 1978-9 survey population estimates were derived from the National Dwelling and Housing Survey, ${ }^{2}$ which did not include Wales. For comparison with 1978-9, notification rates by ethnic group in 1983 and 1988 were calculated for England only.

\section{Results}

Copies of 2748 notification forms were received from the medical officers for environmental health for the six months, of which 340 were excluded for the reasons listed in table 1 . For comparison with previous surveys, analyses were restricted to newly notified patients who had not been treated for tuberculosis previously; there were 2163 in 1988 , compared

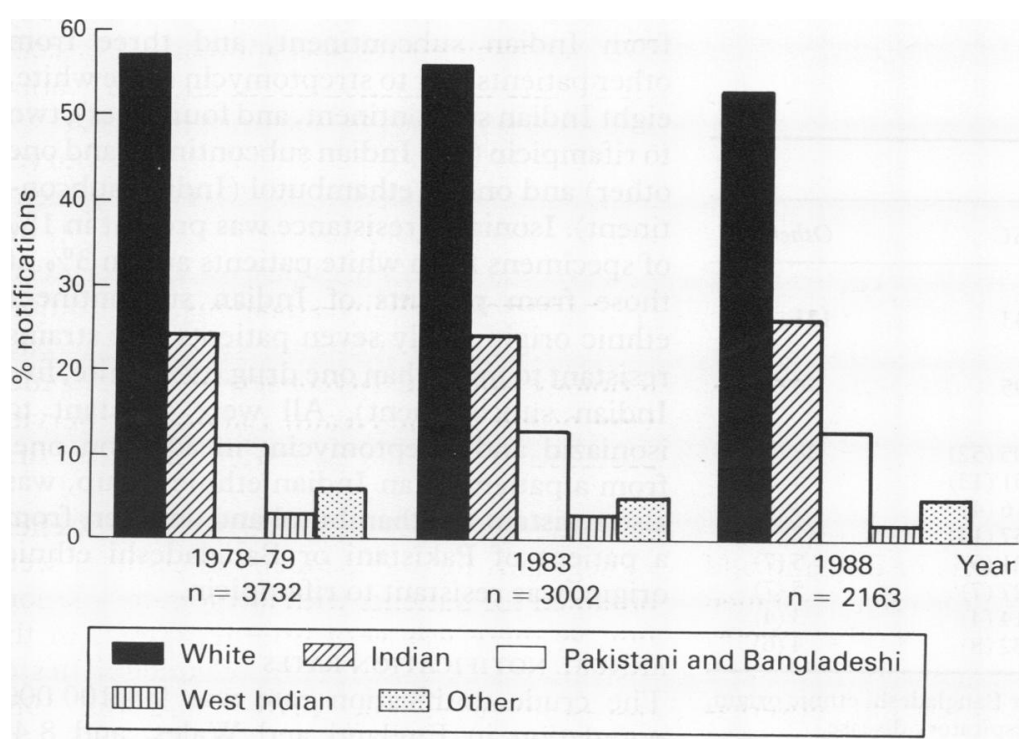

Figure 1 Proportion of tuberculosis notifications in the three surveys by ethnic origin. with 3002 in 1983 and 3732 in 1978-9. Survey forms were obtained for 2149 patients $(99.4 \%$ of the 2163 patients).

\section{ETHNIC GROUP}

There was very little change in the ethnic distribution of cases in the decade covered by the three surveys (fig 1). As was found previously, patients who were either white or of Indian, Pakistani or Bangladeshi ethnic origin accounted for over $90 \%$ of notified cases. In 1988 just over half the patients $(53 \%)$ were white, compared with $57 \%$ in $1978-9$. There was a corresponding slight increase in the proportion of patients of Indian subcontinent ethnic origin (ISC)-that is, Indian, Pakistani, and Bangladeshi-from $35 \%$ in $1978-9$ to $39 \%$ in 1988. Although most of the patients in the Indian subcontinent ethnic groups in 1988 were born abroad, 101 of 834 patients (12\%) were born in the United Kingdom, compared with only $6 \%$ in $1978-9$.

\section{SEX AND AGE}

As in earlier surveys, the sex and age distributions of the white patients differed from those of patients of Indian subcontinent ethnic origin (fig 2). Of the 1142 white patients, $737(65 \%)$ were male, compared with $406(48 \%)$ of the 843 patients in the Indian subcontinent ethnic group. The white patients were on average older than those of Indian subcontinent origin: $625(55 \%)$ of the former were over the age of 55 years compared with only $135(16 \%)$ of the latter and, of the 834 patients below the age of 35 years, $477(57 \%)$ were of Indian subcontinent ethnic origin.

\section{TYPE OF DISEASE}

Respiratory disease alone (that is, affecting the lungs, pleura, or intrathoracic lymph nodes) accounted for $1465(68 \%)$ cases and non-respiratory disease alone for $542(25 \%) ; 156(7 \%)$ patients had both. The distribution of disease varied, however, with ethnic origin: whereas $909(80 \%)$ of white patients had only respiratory disease, $185(16 \%)$ had only non-respiratory disease, and $48(4 \%)$ had both, among those of Indian subcontinent ethnic origin the corresponding figures were 448 (53\%), 300 $(36 \%)$, and $95(11 \%)$. Thus, as in previous surveys, ${ }^{4}$ a larger proportion of patients of 
Figure 2 Distribution of tuberculosis notifications by sex, age, and ethnic origin in the 1988 survey.
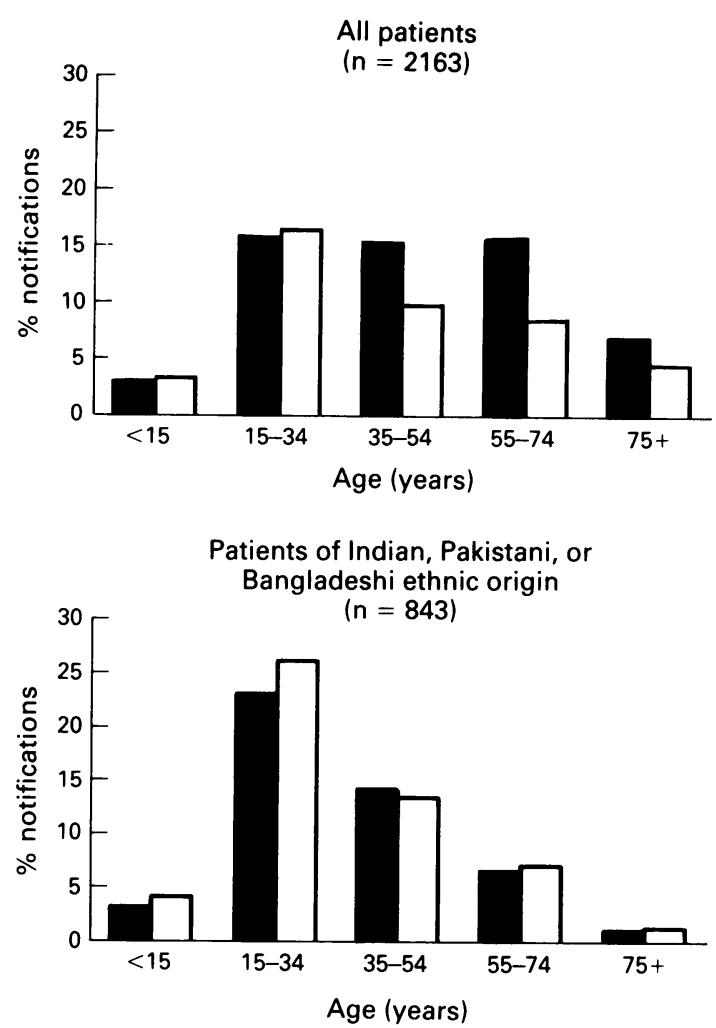

Indian subcontinent ethnic origin had nonrespiratory tuberculosis. Details of sites of disease are given in table 2.

A substantial number of the patients of Indian subcontinent ethnic origin were reported to have tuberculous lymph nodes, both extrathoracic and intrathoracic. Eighty eight $(16 \%)$ of those with respiratory disease and 205 $(52 \%)$ of those with non-respiratory tuberculosis had lymph node disease; in the white patients the comparable figures were $18(2 \%)$ and $86(37 \%)$.

\section{BACTERIOLOGY}

According to information from the reporting physicians, a total of 1443 patients had pulmonary tuberculosis, $89 \%$ of all those with

Table 2 Disease classification by ethnic origin

\begin{tabular}{llll}
\hline & \multicolumn{2}{l}{ Ethnic origin } & \\
\cline { 2 - 4 } & White & ISC & Other \\
\hline $\begin{array}{l}\text { Respiratory } \\
\text { Total patients }\end{array}$ & & & \\
$\begin{array}{l}\text { Non-respiratory } \\
\text { Total patients }\end{array}$ & 957 & 543 & 121 \\
No (\%) of cases & & & \\
Lymph node & 233 & 395 & 70 \\
Bone and joint & & & \\
Genitourinary tract & $86(37)$ & $205(52)$ & $38(54)$ \\
Abdomen & $31(13)$ & $51(13)$ & $5(7)$ \\
Central nervous system & $65(28)$ & $16(4)$ & $3(4)$ \\
Miliary & $14(6)$ & $57(14)$ & $13(19)$ \\
Abscess & $10(4)$ & $21(5)$ & $5(7)$ \\
Other & $19(8)$ & $27(7)$ & $5(7)$ \\
& $10(4)$ & $14(4)$ & $3(4)$ \\
\end{tabular}

*Forty eight white patients, 95 patients of Indian, Pakistani, or Bangladeshi ethnic origin, (ISC) and 13 "other" patients had both respiratory and non-respiratory disease.

tSome patients had lesions at more than one site; percentages are of total non-respiratory lesions.

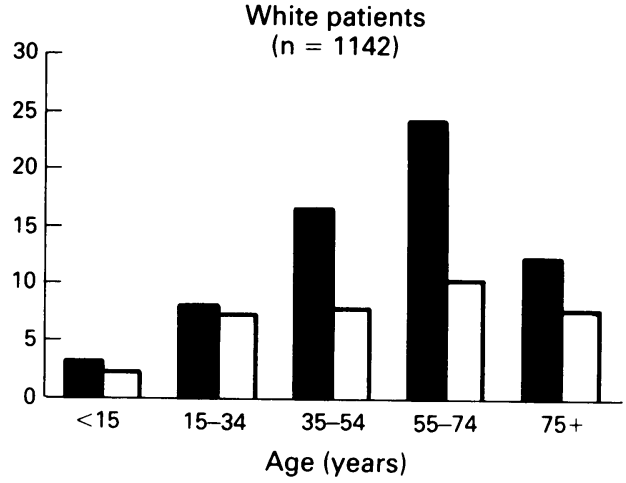

Patients in other ethnic groups ( $n=178)$

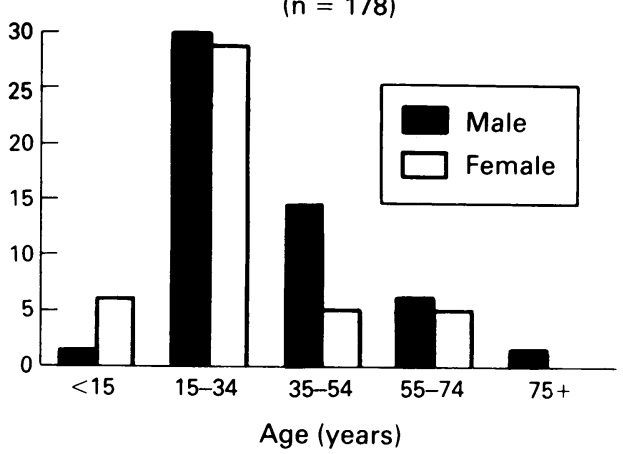

respiratory disease. Bacteriological specimens were examined in $1161(80 \%)$ of the cases of pulmonary disease, of which $939(81 \%)$ had a positive culture for Mycobacterium tuberculosis or $M$ bovis, (5); $614(53 \%)$ also had a positive smear. The proportions were somewhat higher in white patients $(626(83 \%)$ culture positive, including $424(56 \%)$ who were both smear and culture positive) than in those of Indian subcontinent ethnic origin $(247(76 \%)$ and 146 $(45 \%))$

Sensitivity results were available for 840 respiratory specimens, $543(65 \%)$ from white patients and $233(28 \%)$ from patients of Indian subcontinent ethnic origin, of which $32(4 \%)$ grew a strain of $M$ tuberculosis resistant to isoniazid, streptomycin, rifampicin, or ethambutol: 17 to isoniazid (six from white, eight from Indian subcontinent, and three from other patients), 21 to streptomycin (nine white, eight Indian subcontinent, and four other), two to rifampicin (one Indian subcontinent and one other) and one to ethambutol (Indian subcontinent). Isoniazid resistance was present in $1 \%$ of specimens from white patients and in 3\% of those from patients of Indian subcontinent ethnic origin. Only seven patients had strains resistant to more than one drug (two white, five Indian subcontinent). All were resistant to isoniazid and streptomycin: in addition one, from a patient of an Indian ethnic group, was also resistant to ethambutol and another, from a patient of Pakistani or Bangladeshi ethnic origin, was resistant to rifampicin.

ANNUAL NOTIFICATION RATES

The crude notification rate was 9.4/100 000 population in England and Wales, and 8.4/ 100000 after exclusion of those previously 
Table 3 Annual notification rates for newly notified previously untreated patients per 100000 population in England and Wales and by ethnic group for England

\begin{tabular}{|c|c|c|c|c|c|c|c|}
\hline \multirow[b]{2}{*}{ Country } & \multirow[b]{2}{*}{ Ethnic origin } & \multicolumn{2}{|l|}{ 1978-9 } & \multicolumn{2}{|l|}{1983} & \multicolumn{2}{|l|}{1988} \\
\hline & & $\begin{array}{l}\text { Population } \\
\text { estimate } \\
\text { (1000s) }\end{array}$ & $\begin{array}{l}\text { Rate/ } \\
100000\end{array}$ & $\begin{array}{l}\text { Population } \\
\text { estimate } \\
\text { (1000s) }\end{array}$ & $\begin{array}{l}\text { Ratel } \\
100000\end{array}$ & $\begin{array}{l}\text { Population } \\
\text { estimate } \\
\text { (1000s) }\end{array}$ & $\begin{array}{l}\text { Ratel } \\
100000\end{array}$ \\
\hline England & $\begin{array}{l}\text { White } \\
\text { Indian } \\
\text { Pakistani and Bangladeshi } \\
\text { West Indian } \\
\text { Other } \\
\text { All }\end{array}$ & $\begin{array}{r}43320 \\
525 \\
248 \\
514 \\
425 \\
45779 \star\end{array}$ & $\begin{array}{r}9.4 \\
354 \cdot 0 \\
353 \cdot 0 \\
30 \cdot 0 \\
97 \cdot 0 \\
16 \cdot 4\end{array}$ & $\begin{array}{r}42994 \\
773 \\
422 \\
494 \\
634 \\
46164^{\star}\end{array}$ & $\begin{array}{r}6 \cdot 9 \\
178 \cdot 0 \\
169 \cdot 0 \\
30 \cdot 0 \\
47 \cdot 0 \\
12 \cdot 2\end{array}$ & $\begin{array}{r}43938 \\
800 \\
541 \\
464 \\
792 \\
46829 \star\end{array}$ & $\begin{array}{r}4 \cdot 7 \\
134 \cdot 6 \\
100 \cdot 5 \\
29 \cdot 2 \\
25 \cdot 9 \\
8 \cdot 6\end{array}$ \\
\hline $\begin{array}{l}\text { Wales } \\
\text { England and Wales }\end{array}$ & 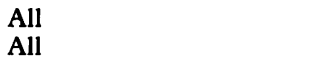 & $\begin{array}{r}2768 \\
48547\end{array}$ & $\begin{array}{l}13 \cdot 5 \\
16 \cdot 3\end{array}$ & $\begin{array}{r}2778 \\
48942\end{array}$ & $\begin{array}{r}8 \cdot 7 \\
12 \cdot 0\end{array}$ & $\begin{array}{r}2823 \\
49652\end{array}$ & $\begin{array}{l}5 \cdot 3 \\
8 \cdot 4\end{array}$ \\
\hline
\end{tabular}

^Includes 747000 in 1978-9, 847000 in 1983, and 296000 in 1988 whose ethnic origin was unclassified.

treated for tuberculosis. Rates had fallen since the surveys of 1978-9 and 1983 in all ethnic groups except the West Indian (table 3 ). The reduction from $9 \cdot 4 / 100000$ in the white population in 1978-9 to 6.9 in 1983 and 4.7 in 1988 represents an annual percentage decline of $7.0 \%$ between the first two surveys and $7 \cdot 4 \%$ between the second and the third. Rates in the populations of Indian and of Pakistani and Bangladeshi ethnic origin had also fallenalthough, as in previous surveys, their rates were 25 times as great as those of the white population.

In all ethnic groups notification rates were highest in older age groups. In the white population the trend with age was apparent in both sexes and in each of the surveys (fig 3 ). The incidence rate in each 10 year age cohort, however, was less in 1988 than in 1978-9. For instance, women in the 25-34 year age group in 1978-9 had a rate of 5.9/100 000; in 1988, when that cohort was $35-44$ years old, the rate was $2 \cdot 3 / 100000$

The annual percentage decline in rates by age group in the white population in England is shown in table 4. Although age specific rates were higher in men than in women in each of

Figure 3 Tuberculosis notification rates in the white population in England by sex and age in the three surveys.

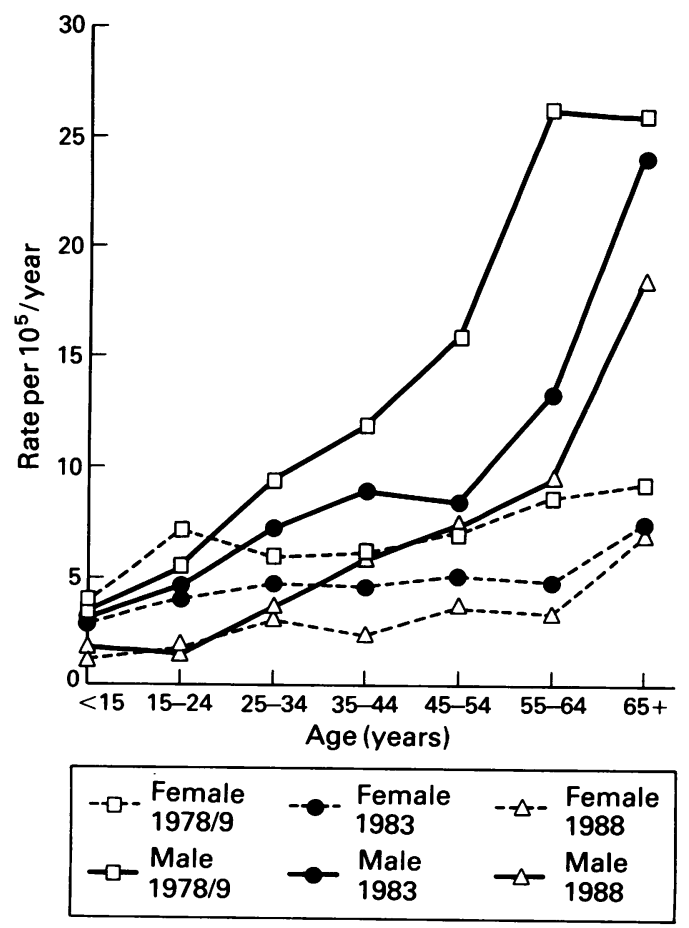

the surveys, the declines in the two sexes were similar: in the younger age groups notification rates had fallen rapidly, but in older age groups rates of decline were slower.

In the population of Indian subcontinent ethnic origin rates were affected by country of birth and length of time since first arrival in the United Kingdom as well as age. Recent immigrants had very much higher rates than those who had lived in the United Kingdom for more than 10 years, and the lowest rates were found in those born in the UK (table 5). For comparison with previous surveys, directly standardised rates were calculated by applying the rates by age and year of entry to the United Kingdom from all three surveys to the 1983 population. The annual percentage decline in the standardised rates was $7 \%$ a year between 1978 and 1983 and $4 \%$ a year between 1983 and 1988. Over the decade there was an annual percentage decline of $4 \%$ in the Indian ethnic group and $8 \%$ in the population of Pakistani or Bangladeshi ethnic origin (data not tabulated here).

There was no change in notification rates in the population of West Indian origin in the decade covered by the three MRC surveys (table 3). The estimated rates were based on small numbers of cases, and the population of West Indian origin in England was on average older in 1988 than in 1978. After standardisation for age and sex, however, there was no evidence of a decline in the tuberculosis notification rates in that population.

Table 4 Annual percentage decline in notification rates by age and sex in the white population in England

\begin{tabular}{|c|c|c|c|c|}
\hline \multirow[b]{3}{*}{ Age (years) } & \multicolumn{4}{|c|}{ Mean annual decline } \\
\hline & \multicolumn{2}{|c|}{$1978-88$} & \multicolumn{2}{|c|}{$1953-88^{\star}$} \\
\hline & Female & Male & Female & Male \\
\hline$<15$ & $12 \cdot 0$ & $7 \cdot 2$ & $10 \cdot 7$ & $9 \cdot 9$ \\
\hline $15-24$ & $14 \cdot 3$ & $13 \cdot 8$ & $12 \cdot 8$ & $12 \cdot 6$ \\
\hline $25-34$ & $7 \cdot 1$ & 9.9 & $10 \cdot 7$ & $9 \cdot 7$ \\
\hline $35-44$ & $10 \cdot 0$ & $7 \cdot 5$ & $9 \cdot 3$ & $8 \cdot 1$ \\
\hline $45-54$ & 6.9 & $8 \cdot 0$ & $6 \cdot 2$ & $7 \cdot 5$ \\
\hline $55-64$ & $9 \cdot 8$ & $10 \cdot 5$ & $5 \cdot 5$ & $7 \cdot 0$ \\
\hline $65+$ & $3 \cdot 1$ & $3 \cdot 7$ & $2 \cdot 7$ & $3 \cdot 7$ \\
\hline Total & $7 \cdot 4$ & $7 \cdot 2$ & $8 \cdot 6$ & $7 \cdot 6$ \\
\hline
\end{tabular}

*Based on all notifications in 1953 , before national rates could be influenced to any important extent by immigration, ${ }^{5}$ and all notifications of white patients from the 1988 survey, including those treated previously. 
Table 5 Annual notification rates in the population of Indian subcontinent ethnic origin in England by age, place of birth, and years since entry to the United Kingdom

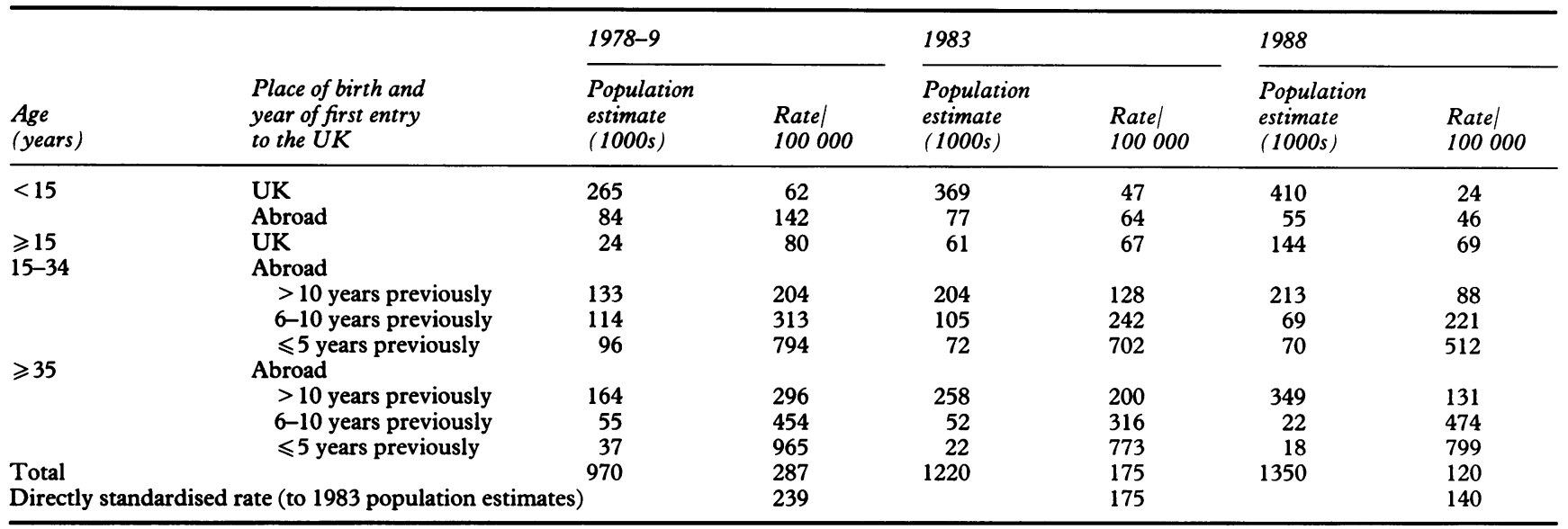

\section{Discussion}

In 1988 there were 5164 notifications of tuberculosis to the Office of Population Censuses and Surveys in England and Wales, corresponding to a rate of $10 \cdot 2 / 100000 .^{6}$ This is higher than the rates estimated for the same year by this survey $(9 \cdot 4 / 100000$, and $8 \cdot 4 / 100000$ when those previously treated for tuberculosis were omitted) because of the exclusion criteria detailed in table 1 . The extent of undernotification is not known, but it is certain that not all patients are notified, and that the above figures therefore underestimate the incidence of tuberculosis.

Over the decade covered by the three MRC surveys there was little change in the characteristics of disease as judged by reported sites of disease, bacteriological results, and initial drug resistance ${ }^{4}$; tuberculosis notification rates, however, continued to fall. In the white population there was a steady reduction over the decade since 1978 in both sexes and in all age groups, consistent with the trend observed since $1953 .^{5}$ The rate of decline in different groups, however, was not uniform. Middle aged and elderly men continued to experience much higher rates of tuberculosis than women, and the rate of decline was lowest in those over the age of 65 years.

The population of Indian, Pakistani, and Bangladeshi ethnic origin in England and Wales continued to have rates of tuberculosis that were about 25 times as high as the white population's. The substantial effects observed previously of country of birth and length of residence in the United Kingdom on notification rates ${ }^{7}$ were reaffirmed. The incidence was unchanged since 1983 in two groups-those over the age of 15 born in the United Kingdom (a very small group in earlier surveys), and those of 35 years or more who had entered the United Kingdom in the previous five yearsand had increased in those of 35 years or more who had entered the United Kingdom 6-10 years previously. These rates, however, were based on small population estimates derived from a sample survey and so may be unreliable. It may be possible to review the findings later by using 1991 census data.
The overall rate of decline in incidence in the population of Indian, Pakistani, and Bangladeshi ethnic origin between 1978 and 1988 was similar to that seen in the white population ( $6 \%$ a year after standardisation for age, place of birth, and year of entry into the United Kingdom, compared with $7 \cdot 2 \%$ a year in the white population without standardisation for age). The rate of decline in the population of Indian subcontinent ethnic origin appeared to be smaller between 1983 and 1988 (4\% a year) than between 1978 and $1983(7 \%$ a year).

Rates of tuberculosis in children are an important index of the success of preventive measures because they represent recent infection. As the number of cases in children in the six months of the survey was small, information was obtained on notifications in children for the whole of 1988. The analysis of these data will be the subject of a separate report.

There was no indication of a slowing in the rate of decline in the incidence of tuberculosis in young men, which some feared would be the consequence of increasing numbers of cases of the acquired immunodeficiency syndrome (AIDS). Five per cent of patients with AIDS reported to the Public Health Laboratory Service AIDS Centre at the Communicable Disease Surveillance Centre by July 1990 were reported to have had tuberculosis. ${ }^{8}$ As the prevalence of the human immunodeficiency virus (HIV) infection increases there may be an effect on the incidence of tuberculosis in some sections of the population.

Since 1988 the numbers of notifications of tuberculosis in England and Wales have increased slightly: from 5164 in 1988 to 5432 in 1989,5204 in $1990,{ }^{9}$ and a provisional total of 5504 in $1991 .^{10}$ Although the sex and age groups, and the geographical areas in which increases have occurred, do not suggest that they are due to HIV infection," the cause remains obscure. The prevention, detection, and treatment of tuberculosis continue to present a challenge to health services, and the maintenance of surveillance is essential to identify groups for which special measures are required. 
This survey succeeded because of the enthusiastic cooperation of all medical officers for environmental health in England and Wales, all chest physicians and general physicians with a specia interest in chest diseases, and many clinicians in other specialties who provided clinical information, as well as nursing staff, secretaries, records clerks of many hospitals and chest clinics, and local authority infectious disease clerks. We thank the and local authority infectious disease clerks. We thank the
Department of Health, the Welsh Office, the Office of PopulaDepartment of Health, the Welsh Office, the Office of Populations Censuses and Surveys, the British Thoracic Society, and several other specialist groups for their help, and in particular the Mycobacterium Reference Unit (Dr P A Jenkins) and the regional centres for tuberculosis bacteriology of the Public Sutherland, and Dr Victor Springett gave valuable advice.

1 British Tuberculosis Association. Tuberculosis among immigrants to England and Wales: a national survey in 1965. A report from the research committee of the British Tuberculosis Association. Tubercle 1966;47:145-56.

2 Medical Research Council Tuberculosis and Chest Diseases Unit. National survey of tuberculosis notifications in England and Wales 1978-9. BMJ 1980;281:895-8.

3 Medical Research Council Tuberculosis and Chest Diseases Unit. National survey of tuberculosis notifications in England and Wales 1983. BMJ 1985;291:658-61.

4 Medical Research Council Tuberculosis and Chest Diseases Unit. National survey of tuberculosis notifications in
England and Wales in 1983: Characteristics of disease. Tubercle 1987;68:19-32.

5 Springett VH, Darbyshire JH, Nunn AJ, Sutherland I. Changes in tuberculosis notification rates in the white ethnic group in England and Wales between 1953 and 1983. J Epidemiol Community Health 1988;42:370-6.

6 Office of Population Censuses and Surveys. Communicable disease statistics, 1988. London: HMSO, 1990.

7 Nunn AJ, Darbyshire JH, Fox W, Johnson DA, Springett VH. Changes in annual tuberculosis notification rates between 1978-9 and 1983 for the population of Indian between 1978-9 and 1983 for the population of Indian
subcontinent ethnic origin resident in England. $J$ Epidemiol Community Health 1986;40:357-63.

8 Watson JM, Meredith SK, Bannister B, Whitmore E, Brander J, Darbyshire JH. Tuberculosis and HIV infection in England and Wales [abstract]. Thorax 1991; tion in $311 \mathrm{P}$

9 Office of Population Censuses and Surveys. Infectious diseases, March quarter 1991. OPCS Monitor MB2 92/3. London: Government Statistical Service, 1992.

10 Office of Population Censuses and Surveys. Registrar General's weekly return for England and Wales. OPCS Monitor WR 91/52. London: Government Statistical Service, 1992.

11 Watson JM, Fern KJ, Porter JDH, Whitmore SE. Notifications of tuberculosis in England and Wales, 1982-1989. Communicable Disease Report 1991;1:13-6. 